\title{
PROFILE
}

Check for updates

Cite this: Chem. Commun., 2021

57, 1066

DOI: $10.1039 / d 1 c c 90026 a$

rsc.li/chemcomm

\section{Contributors to the Emerging Investigators Collection 2020}

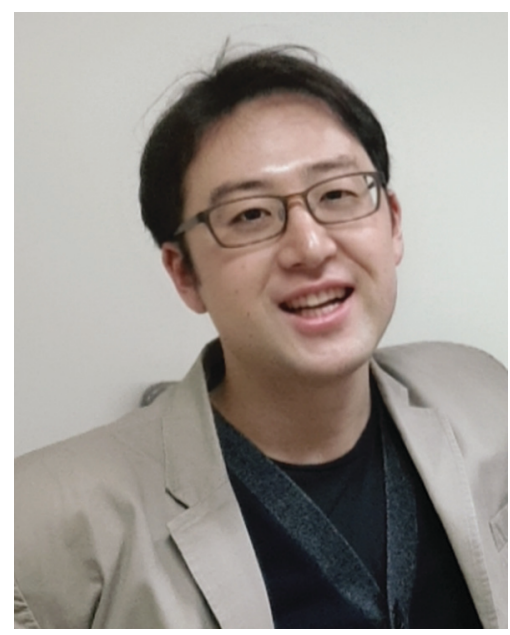

Hyun S. Ahn (a.k.a. Kevin) pursued his PhD studies at the University of California at Berkeley, in the field of inorganic chemistry under the supervision of Prof. T. Don Tilley. Upon conferral of his PhD in 2013, Hyun continued his research at the University of Texas with Prof. Allen J. Bard. Hyun's current research interest spans across both inorganic and electro- chemistry. The main topics researched in his laboratory focus on solving energy related problems: understanding and materializing artificial photosynthetic systems and advanced batteries.

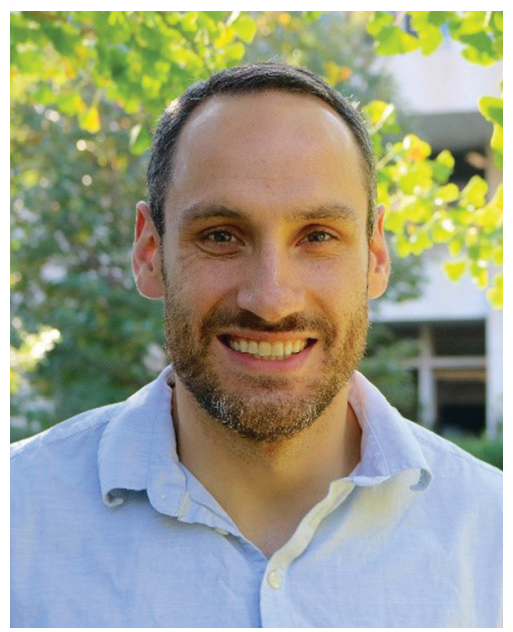

John Anderson graduated with a BS/MS in 2008 from the University of Chicago working with Greg Hillhouse on phosphine complexes of $\mathrm{Ni}$ and their reactivity with small molecules. He began his PhD at MIT and finished at CalTech in 2014 with Jonas Peters working on an Fe catalyst for nitrogen fixation. John then did a postdoc at Northwestern with Dave Harris focusing on materials, particularly metal organic frameworks. He returned to the University of Chicago in 2015 and has been interested in linking the physical characteristics of transition metal centers, including spin and radical character, to reactivity and materials properties.

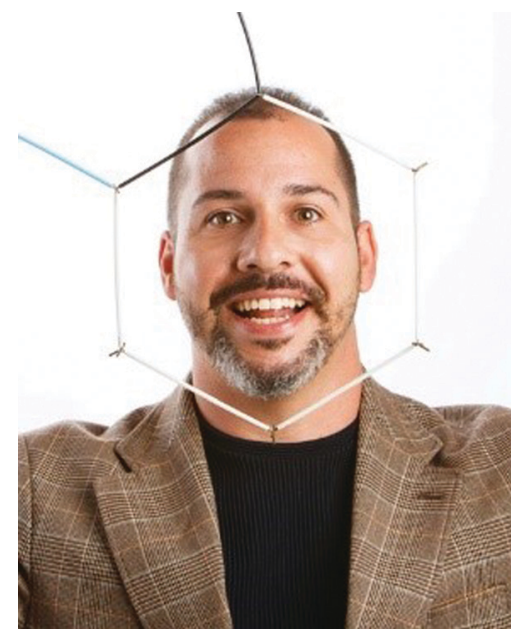

Luis Miguel Azofra loves quantum chemistry as much as the sea. The latter was a gift he received for being born in the Canary Islands, the first is a passion he learned during his PhD in Prof. Alkorta's lab (CSIC, Spain). In 2015, Dr Sun and Prof. MacFarlane introduced him to the field of catalysis (Monash University, Australia), and in 2016 he joined Prof. Cavallo's group as an in silico designer (KAUST, Saudi Arabia). Currently, Dr Azofra is an early-career research leader at Universidad de Las Palmas de Gran Canaria, where he combines his efforts as researcher and lecturer. 


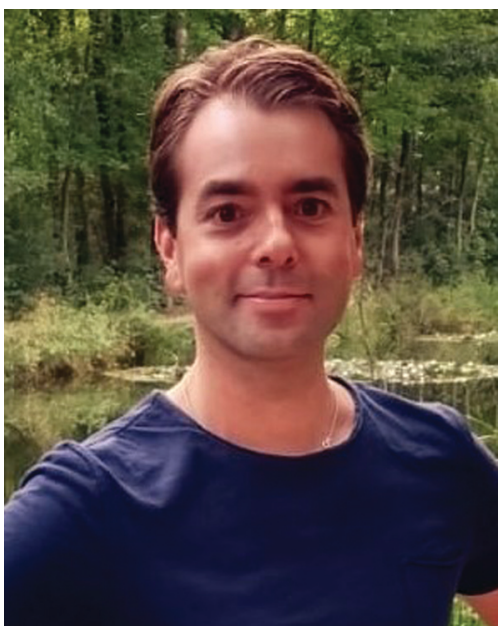

Jonathan Bauer was born in Augsburg (Germany). He studied Chemistry at the Julius-Maximilians-Universität Würzburg (Germany) and received his doctoral degree in 2014 from the Technische Universität Dortmund (Germany) under the supervision of Professor Carsten Strohmann. After postdoctoral studies with Professor David Milstein at The Weizmann Institute of Science (Israel) from 2014 to 2016, he moved back to Regensburg (Germany) and worked as a postdoc with Professor Manfred Scheer. Since 2018, he has been leading an independent research group at the Universität Regensburg working in the fields of Lewis-acidic cations, functionalized siloxanes, and coordination chemistry. Outside of the lab, cooking and singing in a chamber choir are his passions.

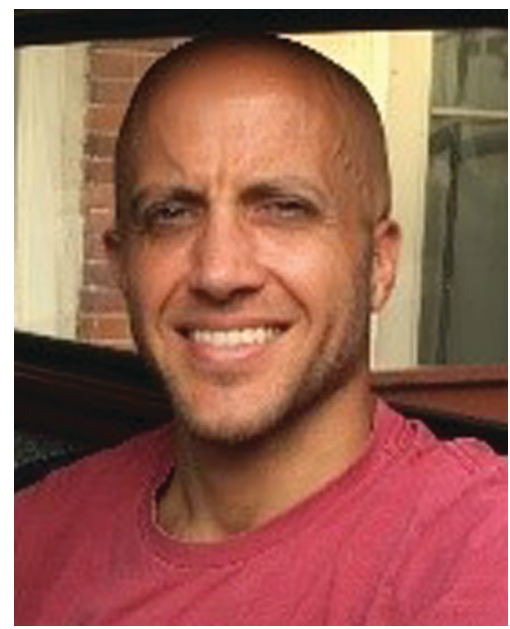

Eric Bloch was born in Wisconsin in 1983 and raised on a dairy farm near Brownsville (population 400). After a stint as the owner (and only employee) of Building
Bloch Construction, he attended UW-Fond du Lac then transferred to UW-Milwaukee. He earned his PhD from UC-Berkeley and did a postdoc at Harvard. He started a faculty position at the University of Delaware in 2016 where his research focuses on the design and synthesis of porous molecules. When not on endless Zoom calls, Bloch's idea of relaxation is working on his recently acquired 1969 International Harvester pickup truck with his wife.

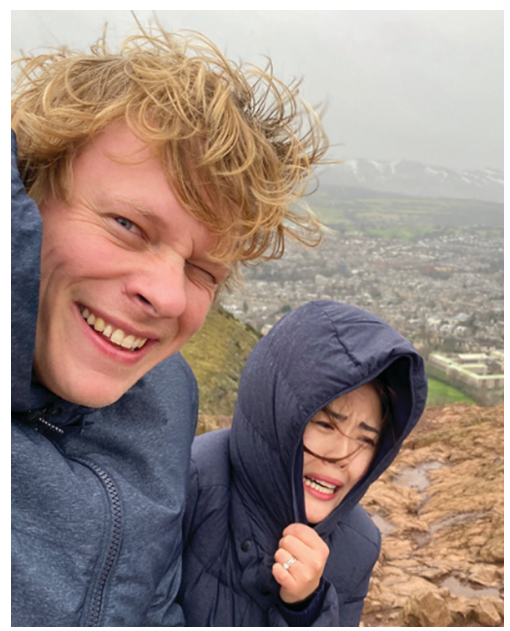

Daniël L. J. (Danny) Broere obtained his $\mathrm{PhD}$ in 2016 at the University of Amsterdam working with Jarl Ivar van der Vlugt. Subsequently, he worked as a Rubicon postdoctoral fellow with Pat Holland at Yale University. There, Danny met his (now) wife and also realized the goal laid out in his Rubicon proposal, albeit in a completely different way than proposed. In September 2018 he started as a tenuretrack assistant professor at Utrecht University where his research focusses on the development of well-defined homogeneous multimetallic catalyst systems. Outside of work, Danny is an avid traveler with a secret agenda to show his wife that there are places with worse weather than The Netherlands.

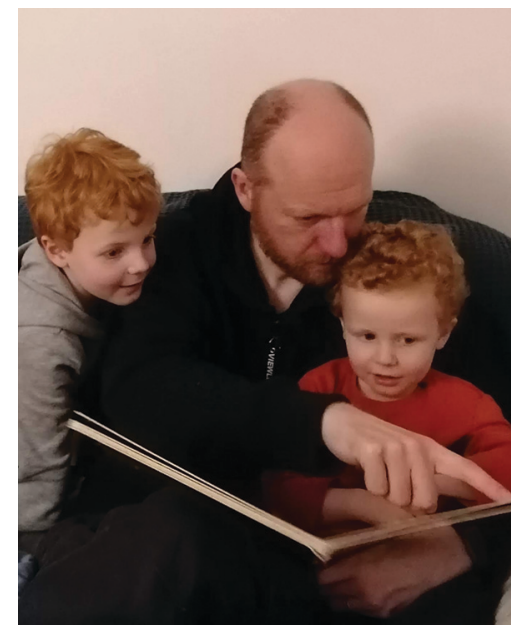

Magnus R. Buchner studied chemistry at the Technische Universität München where he received his $\mathrm{PhD}$ in 2011 under the supervision of Klaus Ruhland. After postdoctoral stays in the groups of Florian Kraus (Munich), Robin Perutz (York) and Sjörd Harder (Erlangen) and a stint in the patent department of the FraunhoferGesellschaft, he started his independent research at the Philipps-Universität Marburg in 2015, funded by the Deutsche Forschungs Gemeinschaft, and since 2019 within the Emmy Noether program. His research interests lie in the coordination, organometallic and bioinorganic chemistry of hard (pseudo) main group metals, with a predilection for beryllium.

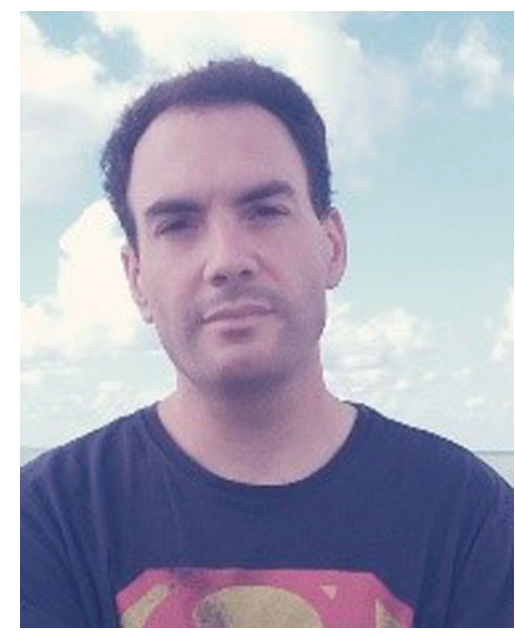

After graduation in 2008, Clément Cabanetos undertook a PhD at the CEISAM laboratory (Nantes, France) on the synthesis of new crosslinkable polymers for nonlinear optical applications. Shortly after his thesis defense, he joined KAUST (Saudi Arabia) as a postdoctoral fellow to 
prepare efficient $\pi$-conjugated macromolecular materials for organic photovoltaics. Thereafter, he was recruited as a CNRS researcher and joined, in 2013, the MOLTECH-Anjou laboratory (Angers, France) to develop new and original concepts for organic electronics. A loving husband (married to Christina) and father of two (Cassandre and Esteban), he enjoys simple things such as listening to rock music, BBQs and surfing.

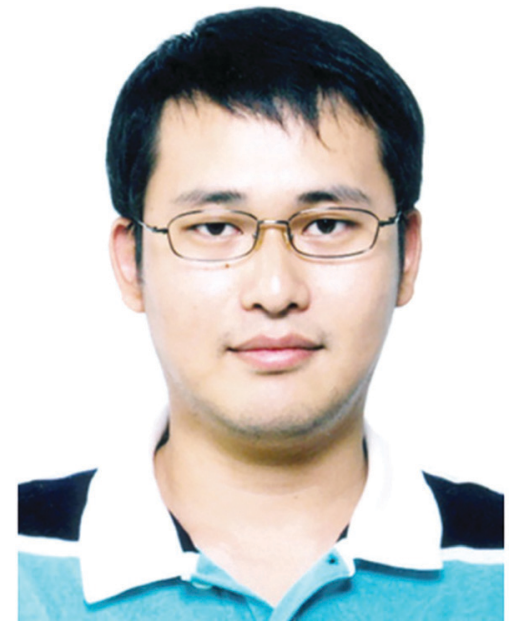

Chen Chen received his BS degree from the Department of Chemistry, Beijing Institute of Technology in 2006, and his PhD degree from the Department of Chemistry, Tsinghua University in 2011 under the direction of Prof. Yadong Li. After postdoctoral work at Lawrence Berkeley National Laboratory with Prof. Peidong Yang, he joined the Department of Chemistry at Tsinghua University as an associate professor in 2015 . His research interests are focused on nanomaterials and catalysis.

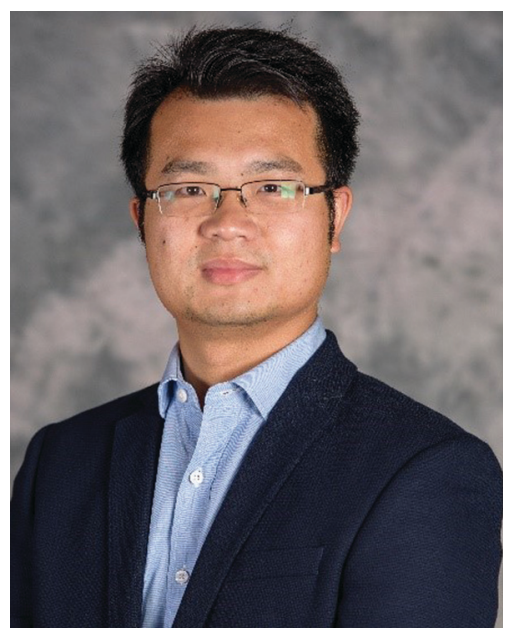

Dr Zheng Chen is an assistant professor in the Department of NanoEngineering, Chemical Engineering and Materials Science Programs at University of California San Diego (UCSD). He received his BS from Tianjin University (2007) and PhD from University of California Los Angeles (2012), both in Chemical Engineering. Then he served as a postdoctoral researcher at Stanford University before joining UCSD in 2016. His research group, the Sustainable Materials and Energy Laboratory (SMEL), mainly focuses on designing and understanding novel molecules, nanostructured materials, functional polymers and their hybrid materials for energy storage and conversion.

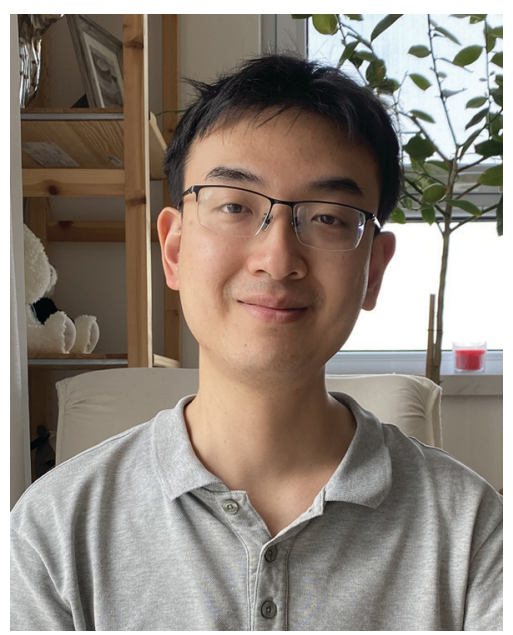

Chi Wai Cheung gained exciting organometallics experience during his doctoral training with Prof. Kin Shing Chan at the Chinese University of Hong Kong. After amazing postdoctoral research on Pd-catalyzed cross-couplings in Prof.
Stephen Buchwald's lab at MIT, he was kindly supported by Prof. Xile $\mathrm{Hu}$ to indulge in interesting base-metal catalysis at EPFL. In 2017, he began his adventure at Tianjin University as an associate professor with a fruitful collaboration with Prof. Jun-An Ma. His current research interest is focused on organic synthesis based on abundant feedstocks, hopefully providing more attractive synthetic methods like the myriad colors of budgies!

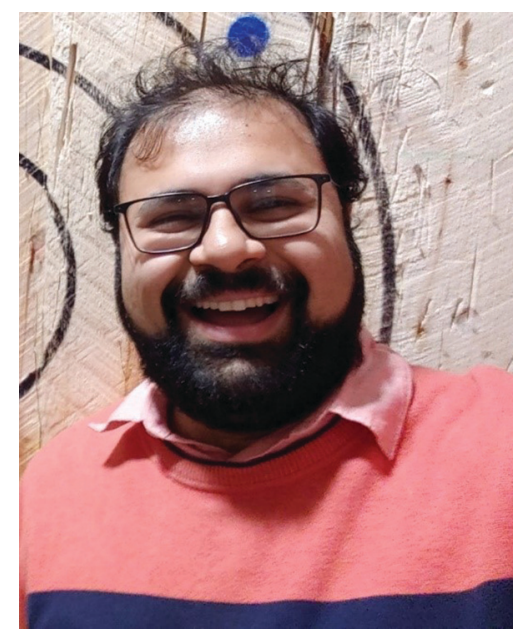

Saurabh Chitnis obtained his PhD with Neil Burford at the University of Victoria (2015) with a 6-month stint at TU-Dresden (Germany) in the group of Jan Weigand. He then performed postdoctoral work with Ian Manners (Bristol) as a Banting Fellow (2015-2017) and Doug Stephan in Toronto (2017-2018). He joined Dalhousie (Canada) in July 2018 where his research is revealing new electronic structures and reactivity at heavy main group centres. In his free time, Saurabh enjoys discovering the coastal beauty of Atlantic Canada with his partner and pretending that he is a master chef, despite evidence to the contrary. 


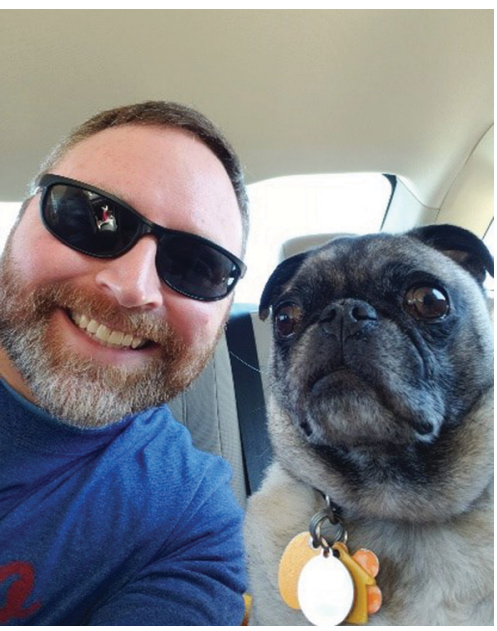

Scott Daly joined the University of Iowa Department of Chemistry in 2014 and was promoted to Associate Professor in 2020. His research focuses on the development of transition metal complexes with non-innocent ligands, XAS investigations of metal complexes with phosphorus ligands, and lanthanide and actinide coordination chemistry. As a US Army veteran, Scott leads a STEM outreach program called the Chemistry Platoon that assists student veterans in chemistry. Outside of work, Scott enjoys downhill skiing, listening to metal bands, and hanging out with his wife and pug.

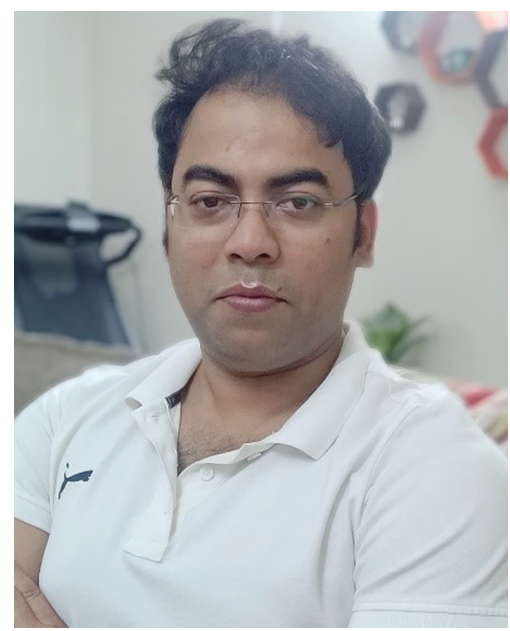

Dibyendu Das is working in the Department of Chemical Sciences of the Indian Institute of Science Education and Research (IISER) Kolkata, West Bengal, India. He grew up in Kolkata, the city of joy located in the eastern part of India. He was always fascinated by how living systems work from the perspective of a (supramolecular) chemist. The intelligence and autonomy of living matter keep inspiring him to attempt synthesizing materials with adaptive properties. Regarding hobbies, Dibyendu absolutely loves cooking Indian cuisine and making fusion food. Swimming and cross country drives also excite him a lot. And to top it all, an 8 month old daughter keeps him busy when he's back home!

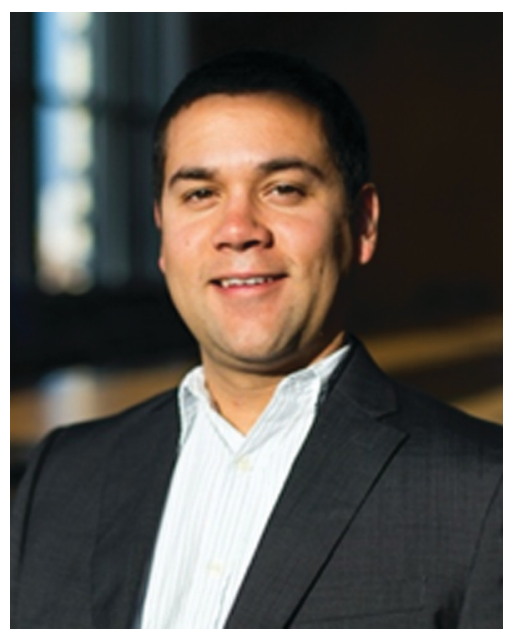

Neil Dasgupta is an Associate Professor in the Departments of Mechanical Engineering and Materials Science at the University of Michigan. He earned his PhD from Stanford University in 2011. Prior to joining the University of Michigan in 2014, he was a postdoctoral fellow at the University of California, Berkeley. He is the recipient of the NSF CAREER Award, the DARPA Young Faculty Award (YFA), the AFOSR Young Investigator Award (YIP), the 3M NonTenured Faculty Award, the ECS Toyota Young Investigator Fellowship, and the AVS Paul Holloway Young Investigator Award. His research focuses on the intersection of materials chemistry, energy conversion, and manufacturing.

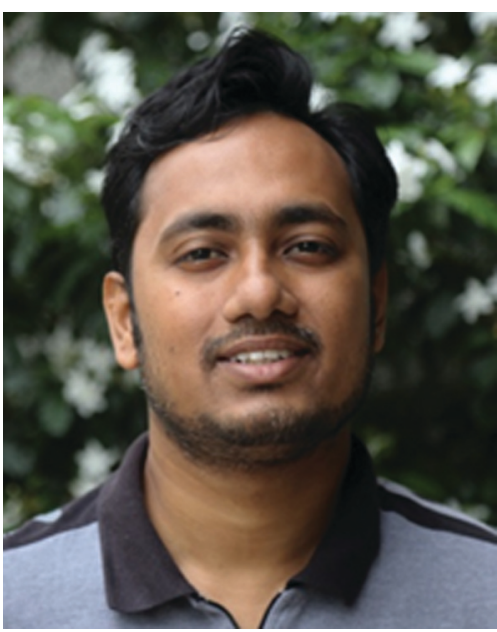

Arnab Dutta probed first of their kind heteronuclear metallopeptides as hydrogenase enzyme models with Prof. Anne K. Jones during his PhD at Arizona State University (2012). Next, he joined Dr Wendy J. Shaw at Pacific Northwest National Laboratory as a post-doctoral researcher and explored new routes to incorporate minimal and essential features of enzyme architecture into artificial catalysts to boost their overall reactivity. A Ramanujan fellowship awardee, Arnab is currently appointed as an assistant professor at IIT Bombay, where he continues his effort to develop bio-inspired, sustainable, and all-weather ready synthetic catalysts for small molecule activation.

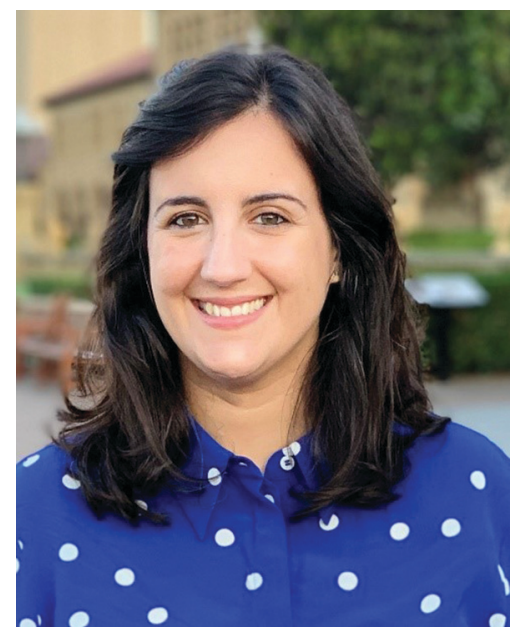

María Escudero-Escribano obtained her $\mathrm{PhD}$ in Chemistry at the Autonomous University of Madrid in 2011. She carried out her postdoctoral research at the Technical University of Denmark and Stanford University, before joining the University of Copenhagen as a 
tenure-track assistant professor in 2017. She is a Villum Young Investigator and a PI of the Center for High Entropy Alloy Catalysis. María's diverse team is focused on elucidating and discovering tailored electrocatalysts for energy conversion and synthesis of green fuels and chemicals. She has received numerous awards in recognition of her achievements in electrochemistry and catalysis.

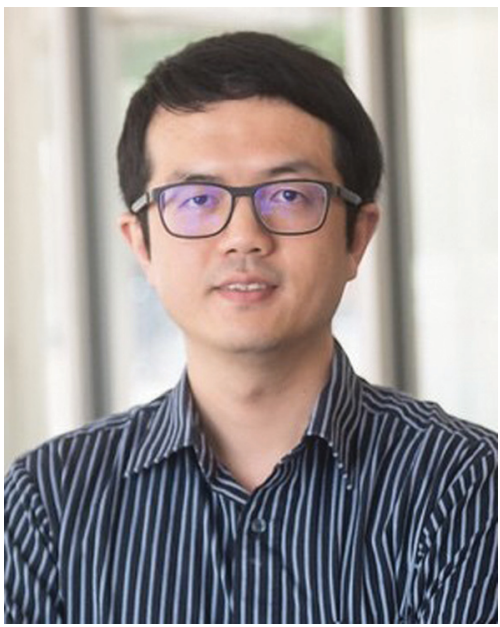

Lei Fang is an associate professor in the Department of Chemistry at Texas A\&M University. He obtained BS (2003) and MS (2006) degrees from Wuhan University. His PhD study was started at University of California Los Angeles in 2006, and completed at Northwestern University in 2010, under the mentorship of Sir Fraser Stoddart. Subsequently, he spent two and a half years at Stanford University as a postdoctoral scholar working with Professor Zhenan Bao. In 2013, he joined the faculty of Texas A\&M University, where he currently leads a multidisciplinary research team focusing on functional organic materials.

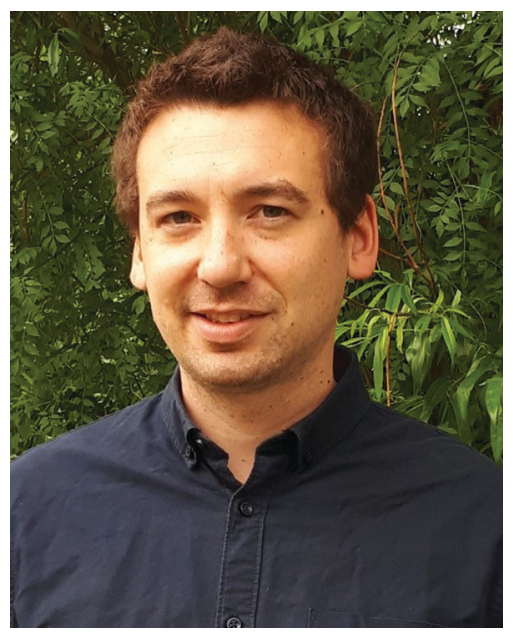

Romain Gautier is currently a research scientist at Centre National de la Recherche Scientifique (CNRS) in the Institut des Matériaux Jean Rouxel. Prior to this position, he obtained a $\mathrm{PhD}$ degree from École Nationale Supérieure de Chimie de Rennes in inorganic and materials chemistry in 2010. Then, he moved to Northwestern University as a postdoc in the group of Prof. Poeppelmeier. In 2019, he received the CNRS Bronze medal and an award from the Chinese "1000 Young Talents Program”. His current research interests include the design, synthesis and characterization of new inorganic and hybrid materials with properties of second harmonic generation and luminescence.

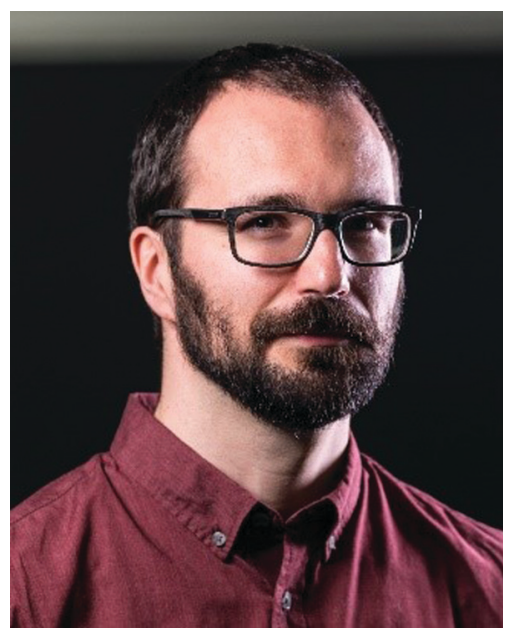

Rafael (Rafa) Gomez-Bombarelli has been an assistant professor at MIT DMSE since 2018. After training as an experimental physical organic chemist (PhD U. Salamanca 2011) his research moved towards fusing machine learning and atomistic simulations for designing materials and their transformations. His group works across molecular, crystalline and polymeric matter, combining novel computational tools in optimization, inverse design, and surrogate modeling with simulation approaches like quantum chemistry and molecular dynamics. Through collaboration with experimentalists, Rafa's group develops new practical materials such as therapeutic peptides, organic electronics for displays, electrolytes for batteries, and oxides for sustainable catalysis.

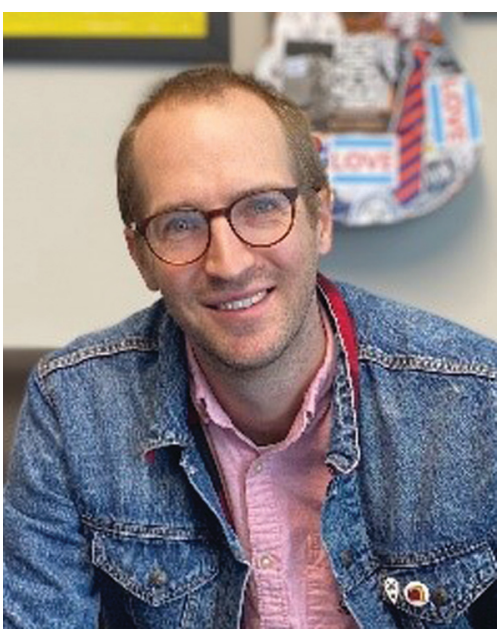

Alexander Grenning is a Chicagoan. He attended Lake Forest College (BA), University of Kansas (PhD) and Boston University (Postdoc) where he trained with Professors William Martin, Jon Tunge, and John Porco, respectively. His independent career began in 2014 in the Department of Chemistry at the University of Florida. He and his group are interested in simplifying complex molecule synthesis! Some of his other interests include: Rock 'n' roll ...his alltime favorite band is Ween! Playing guitar ...but not very well! Microbrews ...mmm very hoppy New England IPAs! Long boarding and mountain biking ...Florida actually has some nice trails (just no mountains!) 


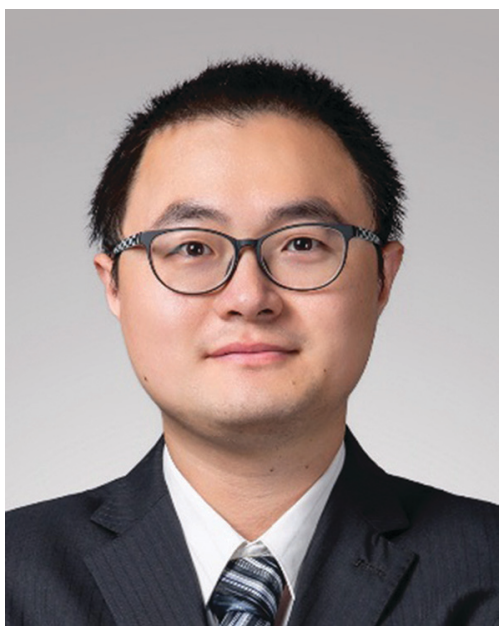

Prof. Cheng $\mathrm{Gu}$ obtained his $\mathrm{PhD}$ in polymer chemistry and physics at Jilin University (China) in 2012 under the supervision of Prof. Yuguang Ma. Then, he joined Prof. Donglin Jiang's group at the Institute for Molecular Science (Japan) and was selected as a JSPS postdoctoral fellow. In 2016, he moved to Kyoto University (Japan) and joined Prof. Susumu Kitagawa's lab as a postdoctoral fellow. In 2017, he joined South China University of Technology as a full professor. He has published more than 20 first/corresponding author papers in scientific journals including Science, J. Am. Chem. Soc., Angew. Chem., Int. Ed., Adv. Mater., Chem. Sci., Chem. Commun. and so on. His research focuses on porous materials and organic optoelectronics.

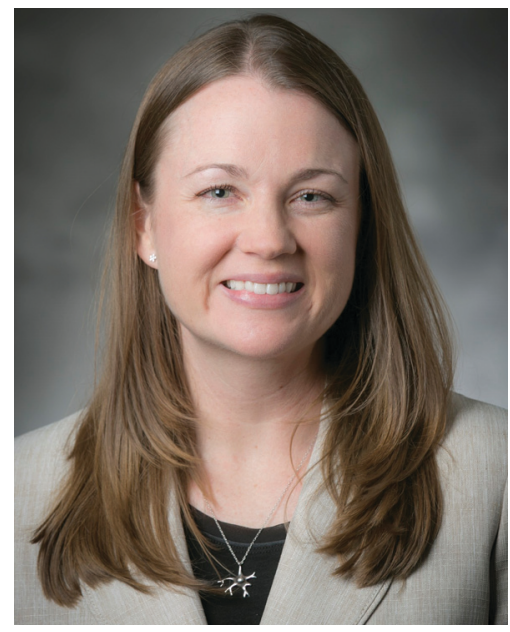

Amanda E. Hargrove is an Associate Professor of Chemistry at Duke University and a past ChemComm Emerging Investigator Lectureship awardee. Prof. Hargrove earned her $\mathrm{PhD}$ in Organic
Chemistry from the University of Texas at Austin followed by a postdoctoral fellowship at Caltech. Her laboratory at Duke works to understand the fundamental drivers of selective small molecule:RNA recognition and to use this knowledge to functionally modulate viral and oncogenic RNA structures. Her passions outside the lab include developing course-based undergraduate research experiences, working toward equity in chemistry at the departmental and national level, and watching old movies with her awesome family.

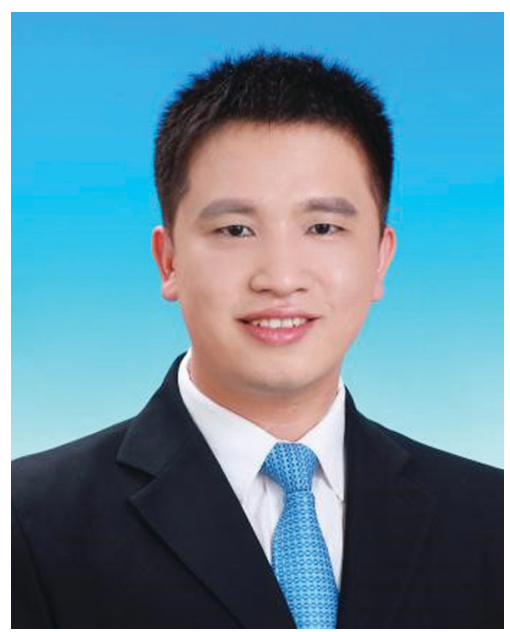

Yue $\mathrm{Hu}$ is an associate professor in the College of Chemistry and Materials Engineering at Wenzhou University. He received his BS from Lanzhou University in 2010. He then moved to Peking University to pursue his PhD degree under the guidance of Prof. Jin Zhang. In July 2015, he joined Wenzhou University to begin his independent career. His current work mainly involves controlled preparation of nano carbon materials and their application in electronic devices, Raman spectroscopy, and electrochemistry.

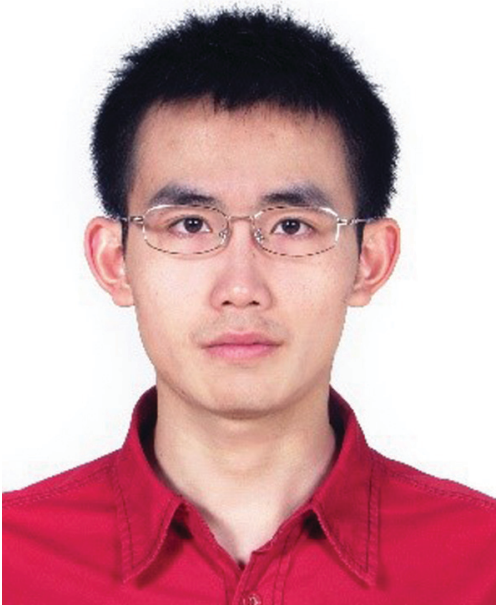

Lingxiang Jiang received his Bachelor and PhD degrees from Peking University, and then performed postdoc research at University of Illinois at Urbana-Champaign with Prof. Steve Granick. In 2016, he joined Jinan University as a principle investigator. $\mathrm{He}$ is working on self-assembly systems that can mimic or are inspired by organelles and subcellular structures. His long-term goal is the integration of isolated biomimetic systems towards whole-cell imitation.

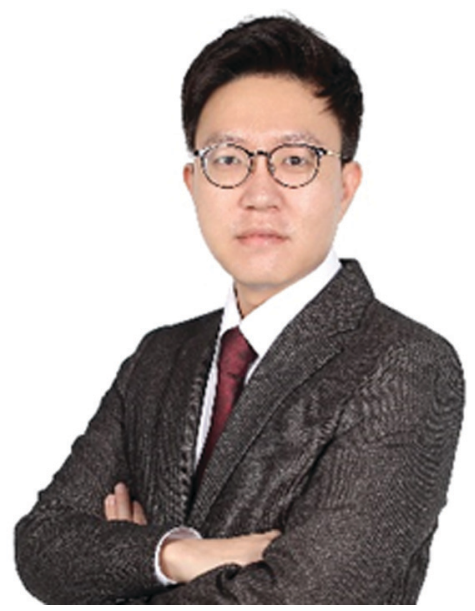

Hyo Sung Jung received his PhD degree in organic chemistry from Korea University in 2013 under the supervision of Prof. Jong Seung Kim. Then, he spent a year in Prof. Jonathan L. Sessler's lab at The University of Texas at Austin. Currently he is an assistant professor in the Department of Biological Sciences at Hyupsung University. To date, his research has led to 35 scientific publications and 12 domestic and international patents in the fields of organic chemistry and biological science. His current 
research interests include the design, synthesis, and biological application of chemical probes for cancer diagnosis and therapy.

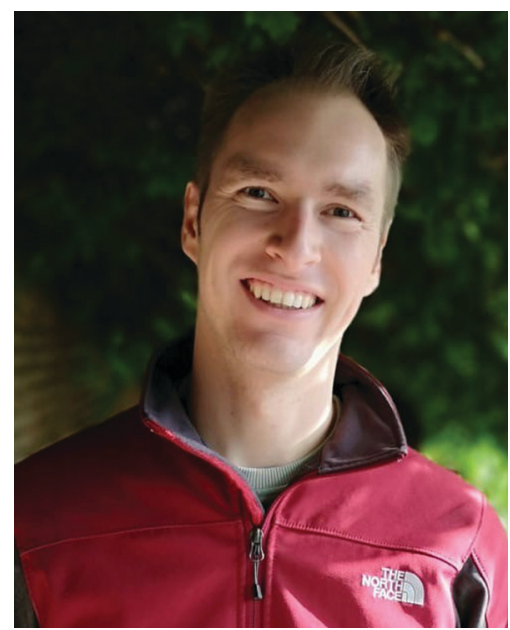

Nikolay Kornienko obtained his BS at the University of Pittsburgh (with Prof. Sanford Asher, 2010 to 2011) and his PhD at the University of California, Berkeley (with Prof. Peidong Yang, 2011 to 2016) studying materials chemistry and electrocatalysis. He then carried out a Royal Society Newton Fellowship at the University of Cambridge with Prof. Erwin Reisner (2016 to 2018) investigating electroactive enzymes and microorganisms. He has recently been appointed as an Assistant Professor at the University of Montreal. His laboratory's research is centered on developing electrocatalysts through rational design and establishing operando spectroscopic techniques to probe catalytic mechanisms.

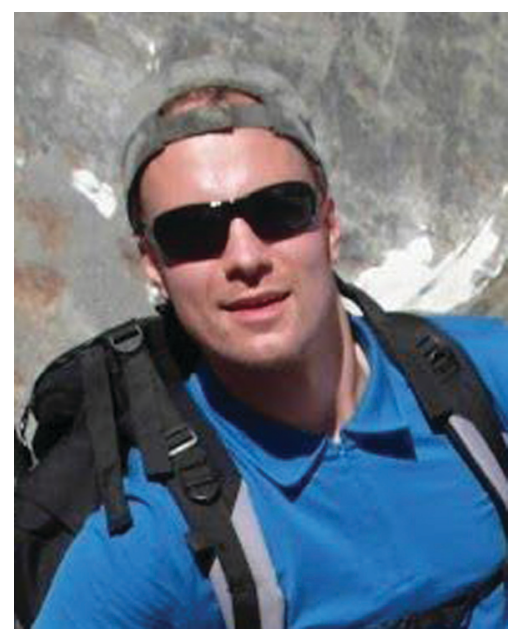

Robert Kretschmer worked as a laboratory technician for several years, before he studied chemistry in Jena. He obtained his $\mathrm{PhD}$ in 2012 under the guidance of Professor Helmut Schwarz and almost decided on a life as a shepherd in the Alps. In the end, a postdoctoral stay with Guy Bertrand interested him more. After leaving San Diego, he started his independent career in 2015 at the University of Regensburg. Since 2019, he has held a tenure track professorship at the Friedrich Schiller University Jena. His research focusses on ligand design and cooperative effects originating from polynuclear systems. Recently he has devoted himself with great commitment to his son and when time permits he likes to play improv theatre and enjoys extended hikes in the mountains.

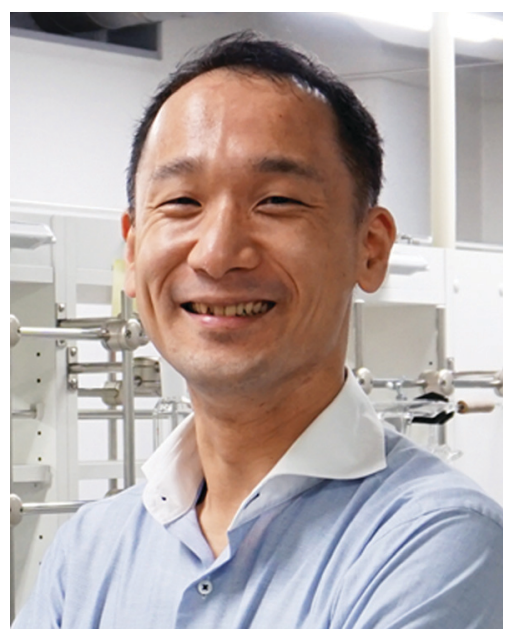

Tetsuro Kusamoto received his PhD degree in inorganic chemistry at the University of Tokyo in 2010. He spent the next two and a half years as a postdoctoral researcher in the group of Dr Reizo Kato at RIKEN. After he spent six years as a project assistant professor (one year) and an assistant professor (five years) in the group of Prof. Hiroshi Nishihara at The University of Tokyo, he began his independent academic career in 2019 as an associate professor at the Institute for Molecular Science, National Institutes of Natural Sciences. He is passionate about developing novel photonic-electronic-magnetic functions and their interplay in open-shell molecular systems, with a particular focus on the correlated spin-luminescence properties of radicals.

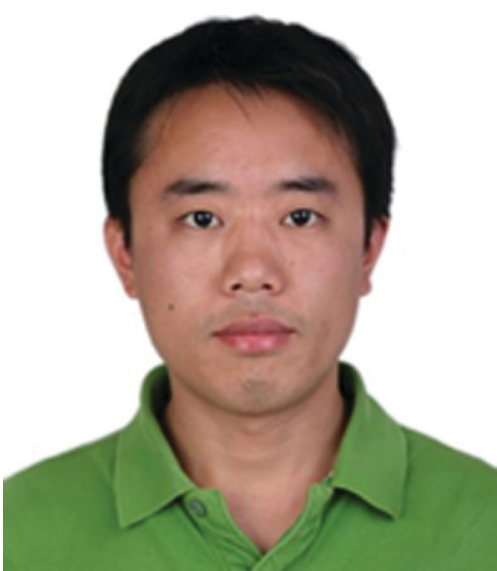

Xu-Bing Li obtained his BS from Wuhan University in 2010 and his $\mathrm{PhD}$ at Technical Institute of Physics and Chemistry (CAS) under the supervision of Prof. Li-Zhu Wu and Prof. Chen-Ho Tung in 2015. Then, he continued his research career in the same group and was promoted to associate professor in 2017. His research interests mainly focus on artificial photosynthesis, including water splitting, carbon dioxide reduction, and photoredox organic transformation.

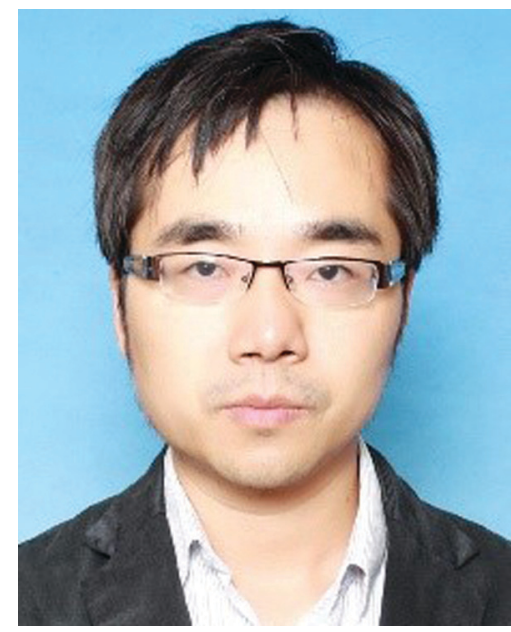

Lu Liu was born in 1980 in Sichuan province, China. He obtained his BS (2001) and PhD (2010, supervisor: Prof. Junliang Zhang) degrees from East China Normal University (ECNU). After conducting postdoctoral research with Prof. Hong Wang at Miami University, he joined ECNU as an associate professor in 2013. In 2016, he was promoted to a full professor. His research interests are selective metal-catalyzed $\mathrm{C}-\mathrm{H}$ bond functionalization and asymmetric catalysis. 


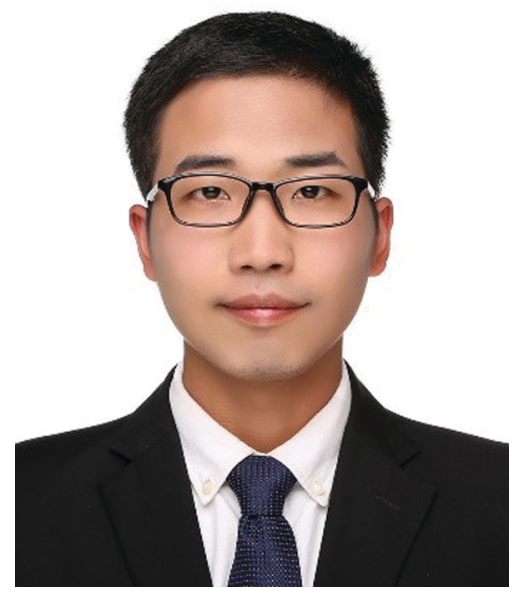

Zhanning Liu received his $\mathrm{PhD}$ degree in Metallurgical Physical Chemistry at the University of Science and Technology Beijing (USTB) under the supervision of Prof. Xianran Xing in 2019. Now he is working at China University of Petroleum (East China) as a postdoctoral fellow with Prof. Daofeng Sun. His current research interests include synthesis of responsive MOFs and exploring their structure-property relationships.

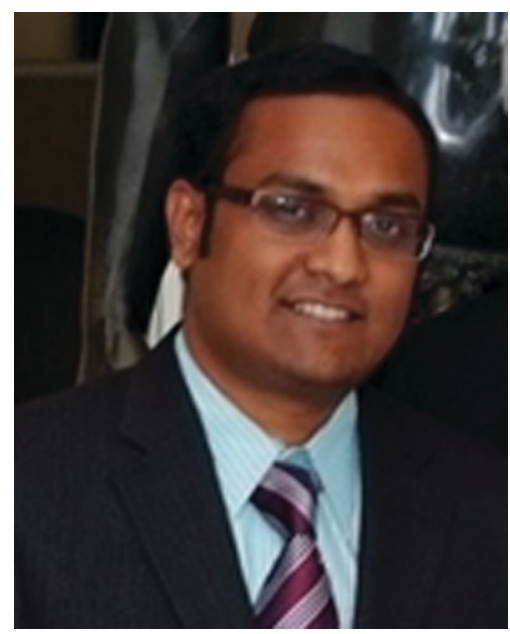

Biplab Maji obtained his PhD (2012) from Ludwig Maximillan Universität München (guide: Prof. Herbert Mayr). He did postdoctoral studies at Chubu University (with Prof. Hisashi Yamamoto) and Westfälische Wilhelms-Universität Münster (with Prof. Frank Glorius). Since 2016, he has been working as an assistant professor in the Department of Chemical Sciences, Indian Institute of Science Education and Research Kolkata. His research focuses on organic synthesis, catalysis, and mechanistic studies. Maji received some awards, including the
Römer-Stiftung (2012), the Förderpreis (2013), an Alexander von Humboldt Fellowship (2015), an INSPIRE Faculty Award (2016), an Early Career Research Award (2016), and a Thieme Journal Award (2019).

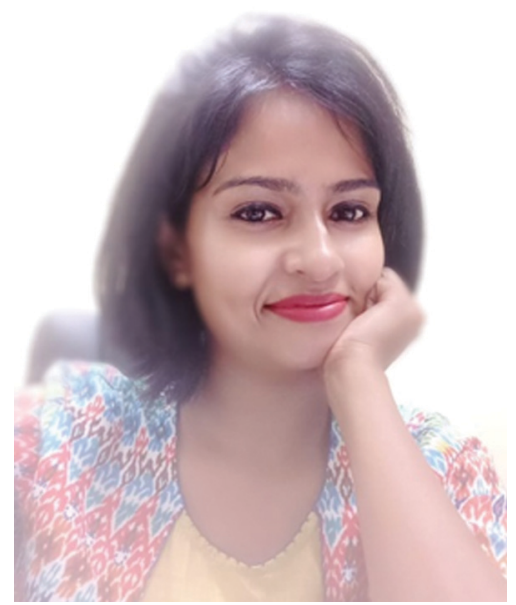

Moumita Majumdar is an Associate Professor in Chemistry at the Indian Institute of Science Education and Research (IISER), Pune, India. She obtained her PhD (2010) at the Indian Institute of Technology (IIT), Kanpur, India, followed by two postdoctoral stints at Osaka University, Japan and at Saarland University, Germany (2010-2014). Her research passion lies in fundamental organometallic chemistry and the organometallic approach towards materials synthesis. She is an ardent advocator for women in science, encouraging women's retention and progression in academia. She is a passionate dancer and enjoys playing with her kid along with her husband.

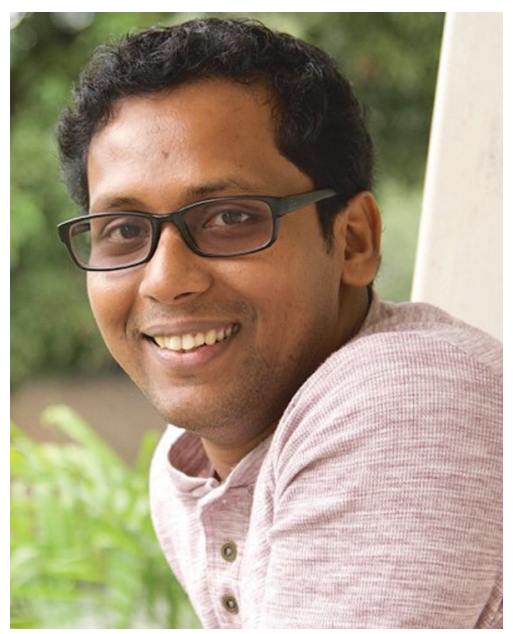

Dr Uttam Manna, currently an Associate Professor at Indian Institute of Technology,
Guwahati (IITG) completed an integrated $\mathrm{PhD}$ at IISc, Bangalore. His $\mathrm{PhD}$ research work secured a Toulouse Medal. In 2011, he went to University of WisconsinMadison for post-doctoral research. He became an associate (2018-2021) of the Indian Academy of Sciences. He received the prestigious NASI Young Scientist Platinum Jubilee Award in 2018 and the INSA Medal for Young Scientists in 2019. Journal of Materials Chemistry A recognized him as an emerging investigator (2018). His research team is involved in designing functional and durable bio-inspired liquid wettabilities for various prospective uses. Besides doing science, he enjoys travelling, music, and photography.

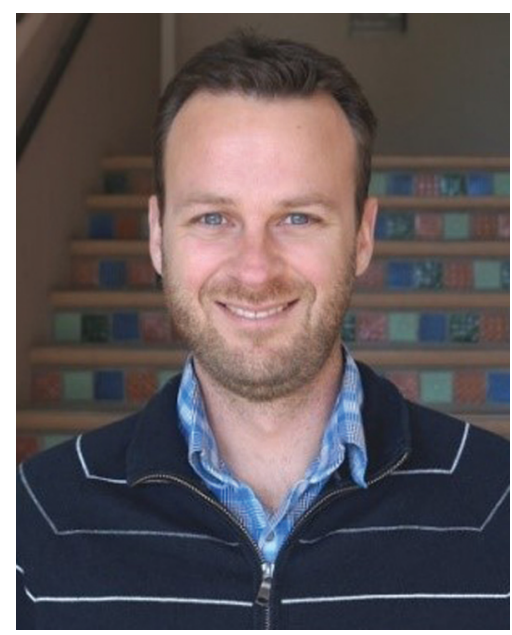

Gabriel Ménard is an assistant professor in Chemistry and Biochemistry at UC Santa Barbara. Gab is Canadian and studied at the University of British Columbia (MSc) in Mike Fryzuk's group prior to moving to the University of Toronto for his PhD in Doug Stephan's group. After a post-doc stint at Harvard University in Ted Betley's group, Gab move to UCSB to start his independent career in 2015 . His group's research is focused on energy storage chemistry, as well as exploring fundamental metal/main-group cooperative reactivity for energy-related applications, such as metal capture and release or $\mathrm{C}-\mathrm{H}$ bond functionalization chemistry. 


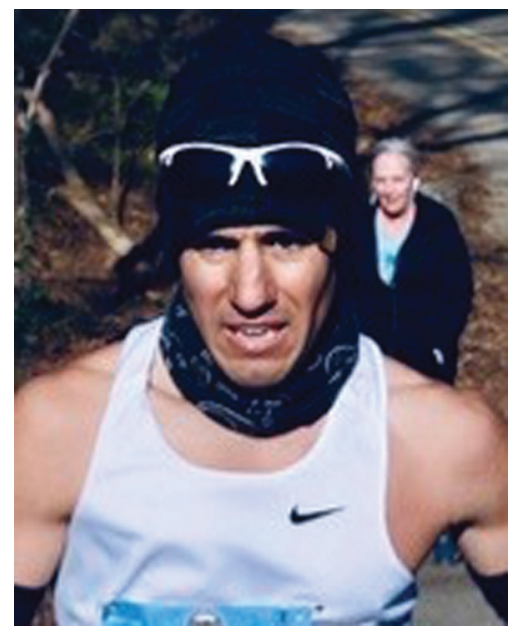

Bradley (Brad) Merner was born in St. John's, NL, Canada and completed his training in chemical synthesis under the direction of Profs Graham Bodwell and Stephen Hanessian. In 2013, he joined the Department of Chemistry and Biochemistry at Auburn University to begin his independent career. Currently, he is the S. D. and Karen H. Worley Associate Professor and directs a talented group of researchers focused on the development of new synthetic strategies for accessing complex organic molecules. Brad enjoys training for distance running events, cooking interesting food, and spending time with his wife Nancy and daughters Abby and Sophie.

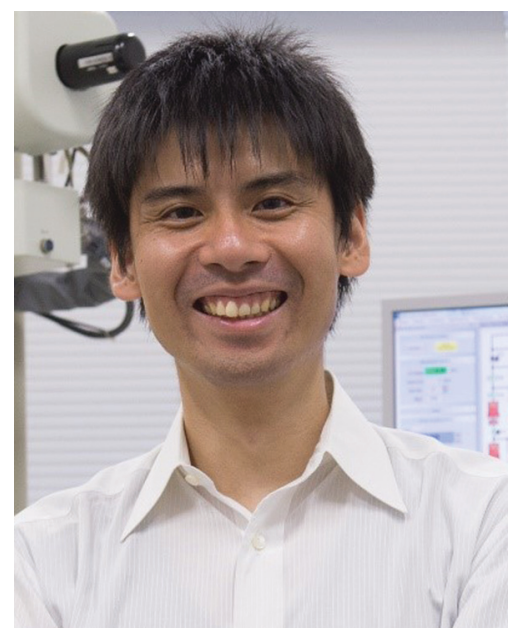

Soichiro Ogi is an assistant professor in the Research Center for Materials Science at Nagoya University, Japan. He earned his MSc and PhD degrees at Kyushu University (2008) and University of Tsukuba (2011), under the supervision of Professor Seiji Shinkai and Professor Masayuki
Takeuchi, respectively. He then became a postdoctoral fellow at National Institute for Materials Science, working on living supramolecular polymerization. In 2014, he joined Professor Frank Würthner's group at the University of Würzburg, Germany, and learned more about the supramolecular chemistry of functional dyes. His current research focuses on the development of methodologies to prepare supramolecular assemblies of $\pi$-conjugated molecules under kinetic and thermodynamic control for electronic and photonic applications.

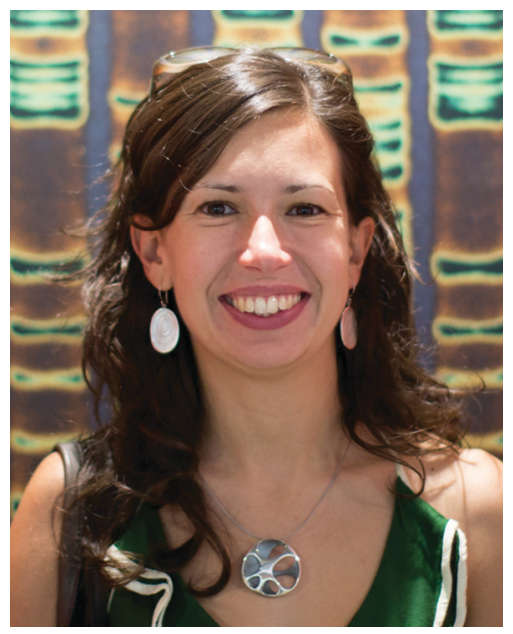

Elena Pazos obtained her PhD in 2012 from the Universidade de Santiago de Compostela under the supervision of Prof. José L. Mascareñas and Prof. M. Eugenio Vázquez. In 2012 she received the Fundación Barrié Postdoctoral fellowship and joined Prof. Samuel I. Stupp at Northwestern University. She then joined Medcom Advance in 2014, and from December 2015 she worked in the group of Prof. Ramón A. Álvarez-Puebla at Centre Tecnològic de la Química. In July 2017 she joined the Universidade da Coruña as an InTalent researcher, where her group is working on the development of new peptide-based materials and biosensors.

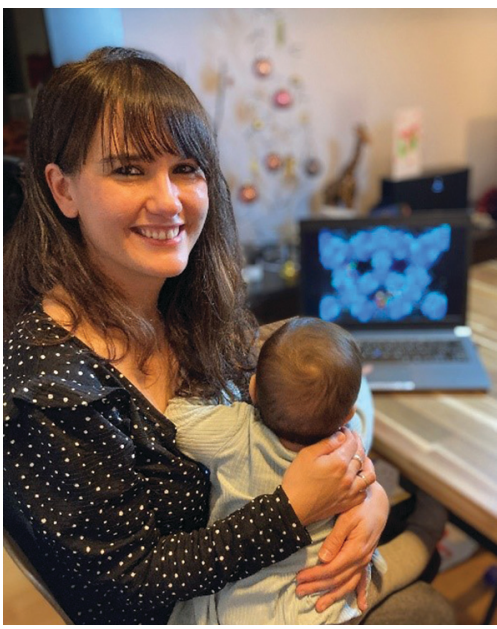

Ana E. Platero-Prats was born in the beautiful Barcelona (Spain). She obtained her $\mathrm{PhD}$ at the Instituto de Ciencia de Materiales de Madrid (Spain). In 2012 she joined Stockholm University (Sweden) as a postdoc, to work with Prof. Zou and Prof. Martín-Matute. In 2014, she moved to the Argonne National Laboratory (USA) to work with Dr Chapman on Pair Distribution Function (PDF) analyses. In 2018, she started her independent career at Universidad Autónoma de Madrid thanks to a TALENT-CM grant, and two years later she received the prestigious Ramón y Cajal Fellowship. When not at work, Ana loves discovering the world through her daughter Alexia's eyes.

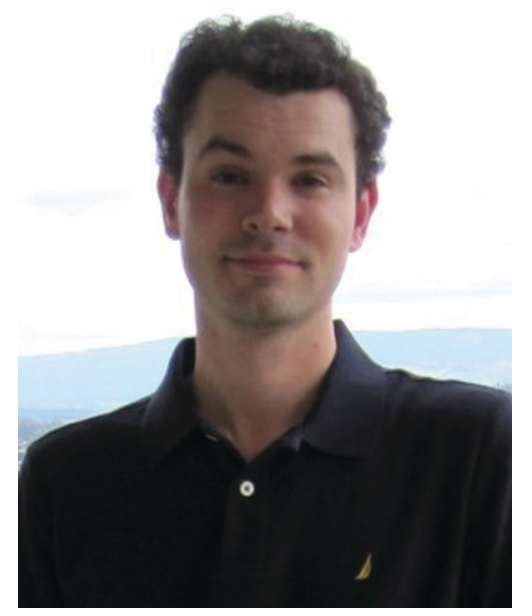

Thomas C. Preston is an Assistant Professor in the Department of Chemistry and the Department of Atmospheric and Oceanic Sciences at McGill University. He received his BSc from the University of Toronto, his MSc from the University of Western Ontario, and his $\mathrm{PhD}$ from the 
University of British Columbia under the supervision of Prof. Ruth Signorell. He completed a NSERC Postdoctoral Fellowship at the University of Bristol under the supervision of Prof. Jonathan P. Reid. His research focuses on the optical trapping and spectroscopy of single particles with an interest in understanding microphysical and chemical processes in atmospheric aerosol particles.

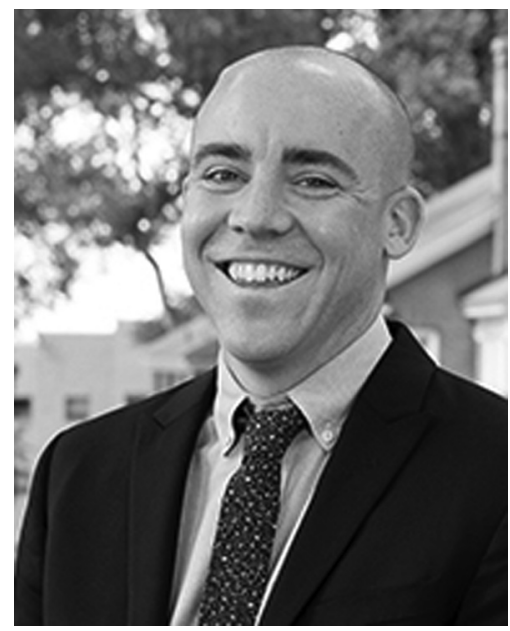

Andrew G. Roberts obtained his PhD in organic chemistry from UCLA (2013) for his studies with Prof. Patrick G. Harran concerning the total synthesis of dimeric pyrrole-imidazole alkaloids. He then completed an NIH Ruth Kirschstein postdoctoral fellowship with Prof. Samuel J. Danishefsky at Memorial Sloan Kettering Cancer Center in New York, where he developed methods for chemical protein synthesis. Currently, Andrew is an Assistant Professor of Chemistry at the University of Utah. The Roberts laboratory is focused on the development of chemoselective methods for peptide ligation and modification as well as efforts toward the chemical synthesis of lasso peptides.

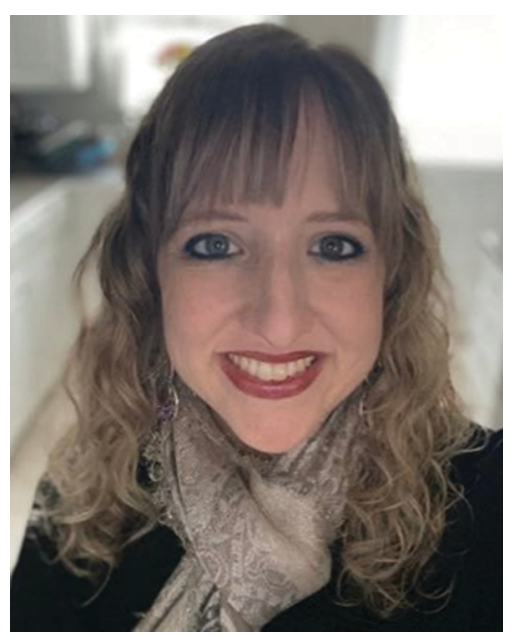

Ashley Ross is an Assistant Professor of Chemistry at the University of Cincinnati and faculty in the Neuroscience Graduate Program. She earned her $\mathrm{PhD}$ from the University of Virginia with Dr Jill Venton and did a post-doc in Dr Rebecca Pompano's lab where she was an American Association of Immunology Careers in Immunology Fellow from 2016 to 2017. Her independent work has been highlighted in the Analyst Emerging Investigator Series. She is currently on the Board of Directors for the Society of Electroanalytical Chemistry, a Microbiome Neurobiology and Disease Scialog Fellow, and on the Features Panel for Analytical Chemistry.

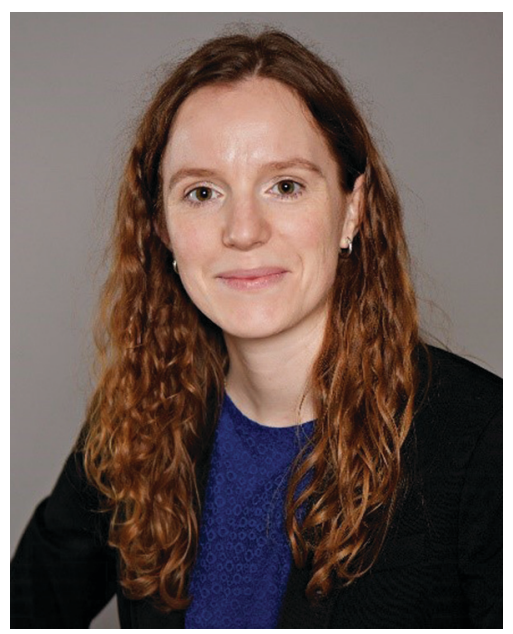

Sophie Rousseaux obtained her PhD from the University of Ottawa in 2012, working with Prof. Keith Fagnou on Pd-catalyzed aliphatic $\mathrm{C}-\mathrm{H}$ bond functionalization reactions. In 2010, she moved to MIT to complete her graduate research with Prof. Stephen L. Buchwald. From 2012 to 2015, she worked with Prof.
Harry L. Anderson, University of Oxford, on the self-assembly of porphyrin nanorings as an NSERC postdoctoral fellow and Glasstone Research Fellow. In July 2015, Sophie joined the Department of Chemistry at the University of Toronto as an Assistant Professor. She has held a Canada Research Chair (Tier 2) in Organic Chemistry since 2016.

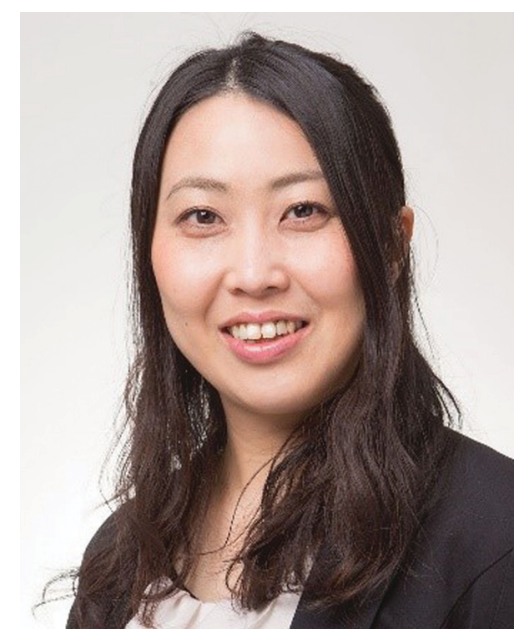

Yoko Sakata is an associate professor at Kanazawa University. She received her PhD degree in 2010 from the University of Tokyo under the supervision of Prof. Mitsuhiko Shionoya. After postdoctoral research at Kyoto University and an ERATO Kitagawa Integrated Pores Project, she moved to Kobe University in 2012 as a project assistant professor. In 2014, she became an assistant professor at Kanazawa University, and since 2018 she has been an associate professor at the same university. Her main research interest is in coordination chemistry, particularly the synthesis and properties of new self-assembled supramolecular complexes. 


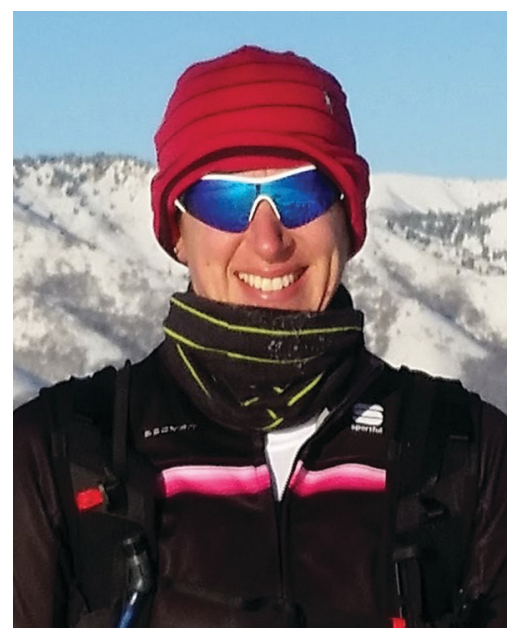

Caroline Saouma started her research career in Steve Lippard's lab while an undergraduate (MIT). She received her $\mathrm{PhD}$ in the lab of Jonas Peters (Caltech) in 2011 and was a postdoc under the supervision of Jim Mayer (University of Washington). Since 2014, she has been an assistant professor at the University of Utah, and her research group is focused on catalyst design for catalytic reductions of $\mathrm{CO}_{2}$. Outside of chemistry, Caroline is an avid athlete, spending countless hours on her bike or cross-country skis. In 2016, she helped the US earn a bronze medal at the World Championships for snowshoe running.

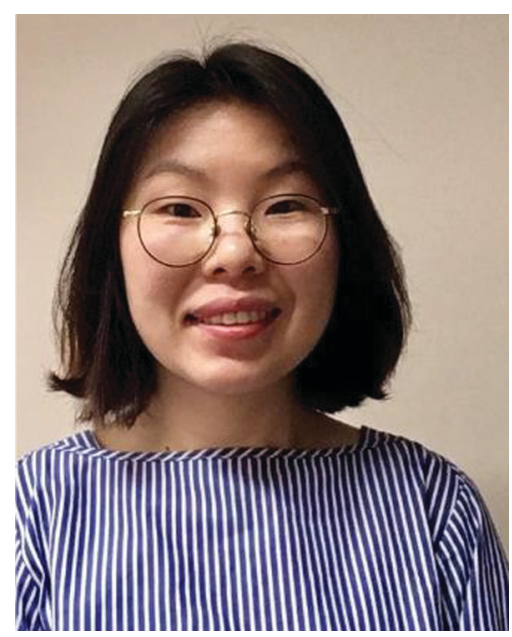

Woon Ju Song obtained her MS under the guidance of Professor Wonwoo Nam at Ewha Womans University and her PhD in the department of chemistry at MIT under the supervision of Professor Stephen J. Lippard. Then, she began her postgraduate studies in Professor Akif F. Tezcan's group at the University of California, San Diego. Since she started her independent career at Seoul National University in 2016 as an assistant professor, her research group has been interested in the design and evolution of metalloproteins, protein self-assembly, and the discovery of novel proteins.

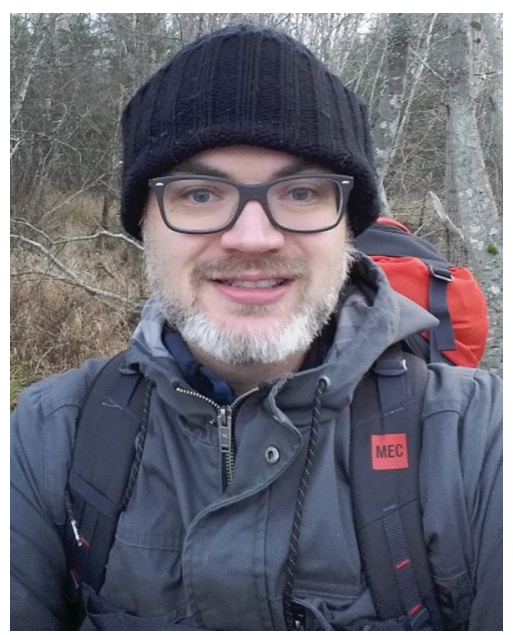

Alex Speed received his $\mathrm{PhD}$ from Harvard University with Prof. David A. Evans in 2012 followed by a postdoctoral fellowship at Boston College with Prof. Amir Hoveyda. Alex began a faculty position at his undergraduate alma mater, Dalhousie University, in 2015. Diverging from a background entirely in natural product total synthesis, his group's research focuses on the development of main-group element-based reagents and catalysts for organic synthesis. The Speed group's research has produced the first reported examples of asymmetric catalysis using diazaphospholenes. The group's other research interests include cyclopropenylidene carbene chemistry, photochemistry with non-metal sensitizers, and sulfur hexafluoride activation. When not at work, Alex enjoys exploring the deep woods of southwest Nova Scotia, beyond the reach of cellphone signals and e-mail.

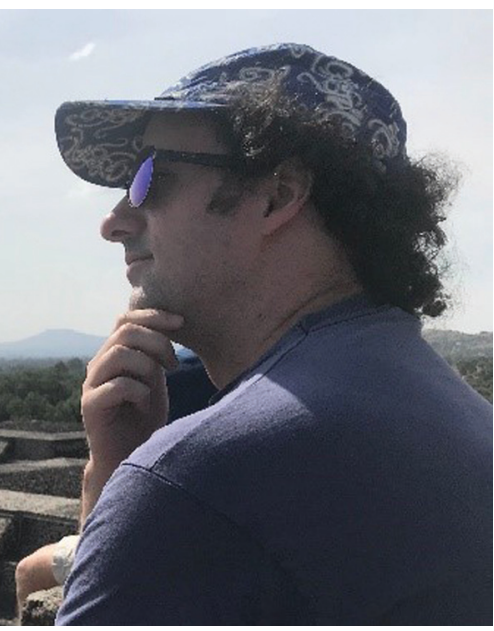

Originally from Amherst, Ohio, the "Sandstone Center of the World," Tom Teets began to pursue chemistry after failed careers as a baseball umpire and athletics groundskeeper. He received a BS in Chemistry from Case Western Reserve University in 2007 and a PhD in Inorganic Chemistry from MIT in 2012, and did postdoctoral research at Caltech from 2012 to 2014 . Tom began his career at the University of Houston in 2014, where his group works on photoluminescent organometallic compounds, photoredox catalyst design, molecular sensors, redox-active ligands, and supramolecular coordination compounds.

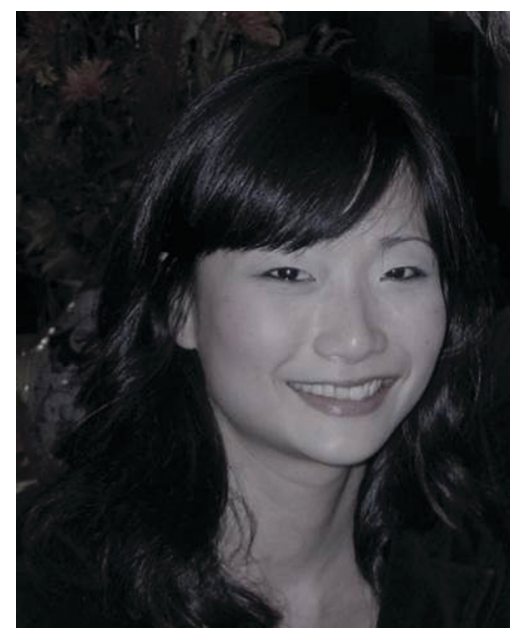

Dr Boon Teo received her PhD in Physical Chemistry at the University of Melbourne under the tutelage of Prof. Franz Grieser and Prof. Muthupandian Ashokkumar. Thereafter, she held postdoctoral positions at Tohoku University (Japan), Aarhus University (Denmark) and the University of Oxford (U.K.) before taking up her first 
lectureship at Monash University in 2017. Currently she is working in the private sector but is still actively involved in her PhD students' research projects at Monash University. Her research interests are broadly in the areas of soft matter and colloidal materials, with focused expertise in ultrasound, biopolymers and (bio-)colloidal systems.

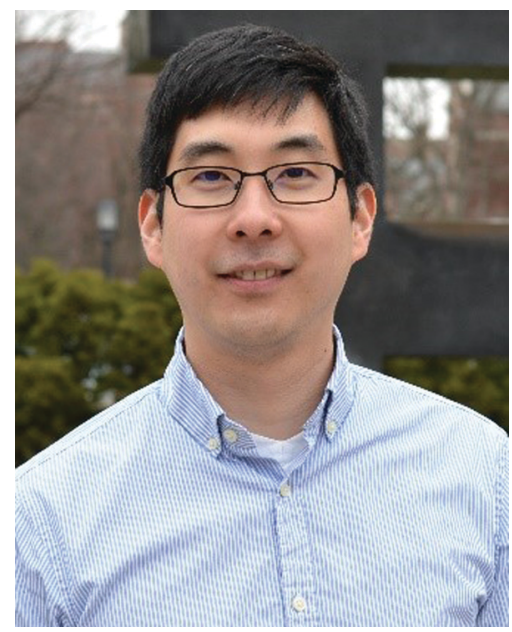

Christopher Uyeda was born and raised in Vancouver, Canada. He was an engineering major at Columbia University and was drawn into the world of chemistry through undergraduate research with Prof. Ronald Breslow. Chris obtained his $\mathrm{PhD}$ in 2011 from Harvard University under the supervision of Prof. Eric Jacobsen and was a postdoctoral researcher in Prof. Jonas Peters's group at Caltech. In 2013, Chris started his independent career at Purdue University where he is currently the Richard B. Wetherill Associate Professor of Chemistry. His research group is on a mission to show that sometimes two metals are better than one.

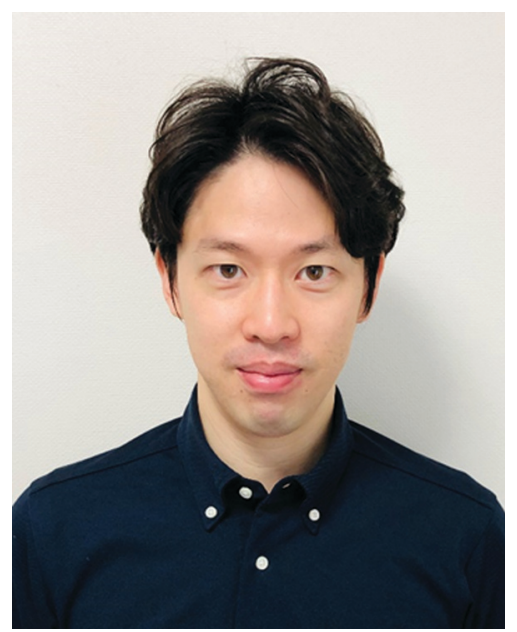

Go Watanabe received his $\mathrm{PhD}$ in Applied Physics from Waseda University in 2011 under the supervision of Prof. Yuka Tabe. After working as a research associate in the same group, he joined the Department of Physics, School of Science, Kitasato University in 2012 as an assistant professor. In 2020, he was promoted to a junior associate professor. His research aims to understand the structure and dynamics of liquid crystals, organic semiconductors, polymers, and biomolecules based on computational science.

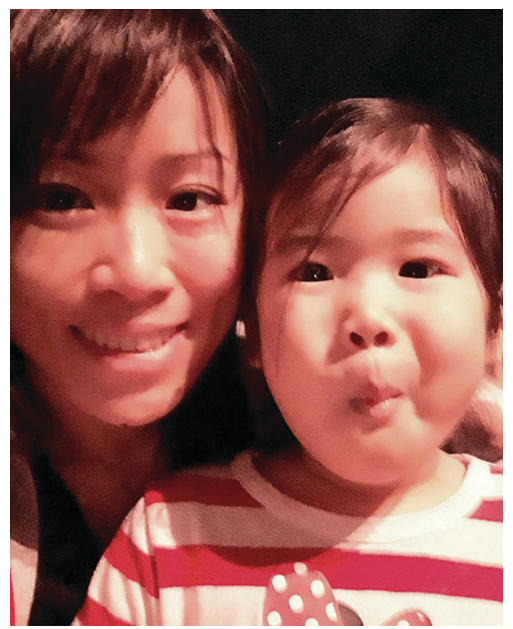

Judy $\mathrm{Wu}$ is short, sometimes impatient, and has often had quite lucky encounters. She earned a BS in Chemistry from TungHai University, Taiwan, and a PhD with Paul Schleyer at the University of Georgia. Her younger self would be surprised that she became a computational chemist/ physical organic chemist. Judy started her independent career at the University of Houston in 2015, and has received multiple awards including an NSF Career
Award, an NIH Maximizing Investigators' Research Award, and a Sloan Research Fellowship. Her research interests span organic chemistry, photochemistry, and supramolecular chemistry. She enjoys long walks, sketching, and playing the ukulele.

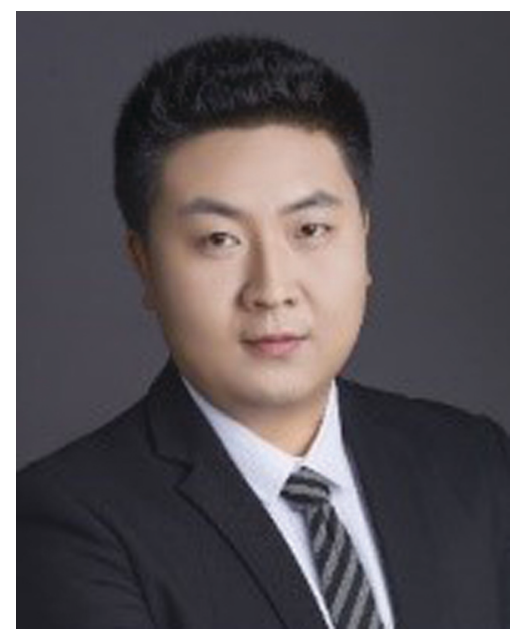

Jin Xie is currently a professor of organic chemistry at Nanjing University. He was born in Chongqing, China, in 1985 . He received his Bachelor's degree from Northeast Forestry University in 2008, and his $\mathrm{PhD}$ in 2013 from Nanjing University working under the direction of Prof. Chengjian Zhu. From 2014 to 2017, he was a postdoctoral research associate at Heidelberg University. In 2017, he returned to Nanjing University to start his independent career. His current research interests lie in synthetic methodology development and mechanism study with the concept of catalysis in diversity in bimetallic chemistry and radical chemistry. 


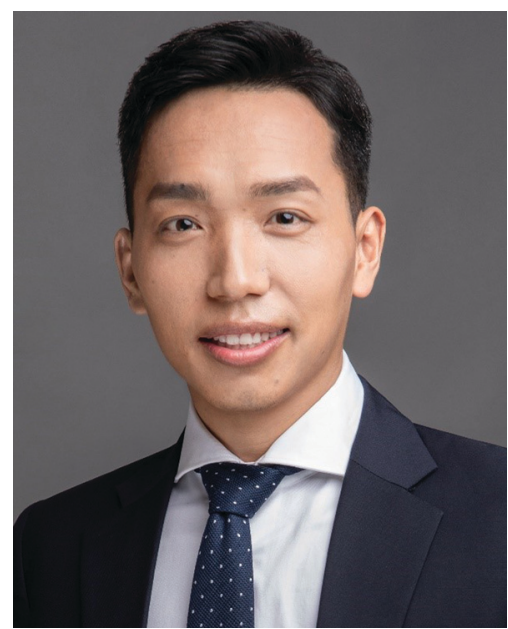

Tao $\mathrm{Xu}$ graduated from East China University of Science and Technology in 2007. He received his MS and PhD in organic chemistry from Shanghai Institute of Organic Chemistry, CAS (SIOC) under the supervision of Professor Guosheng Liu. After one year's experience in process development in industry, he joined Professor Xile Hu's group for postdoctoral studies at École Polytechnique Fédérale de Lausanne (EPFL), Switzerland in 2013. In 2017, he started his independent career as a professor at Tongji University, China. His research is focused on the development of new organometallic catalysts, novel synthetic methodologies and small molecular activation.

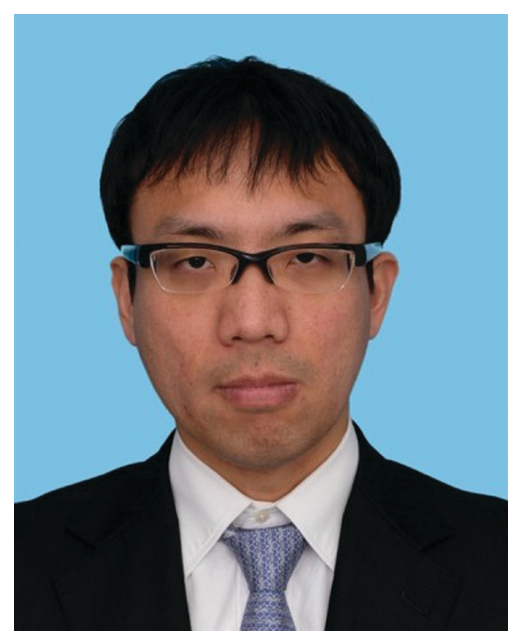

Ryohei Yamakado is an assistant professor in the Department of Organic Materials Science, Graduate School of Organic Materials Science, Yamagata University. He received his $\mathrm{PhD}$ degree in 2014 from Nagoya Institute of Technology, under the guidance of Prof. Koji
Takagi and Prof. Masato Suzuki. From 2014 to 2017, he was a postdoctoral fellow in the group of Prof. Hiromitsu Maeda at Ritsumeikan University. Since 2014, he has been in his current position at Yamagata University, Japan. His research interests include supramolecular chemistry, synthetic polymer chemistry, and organic materials science.

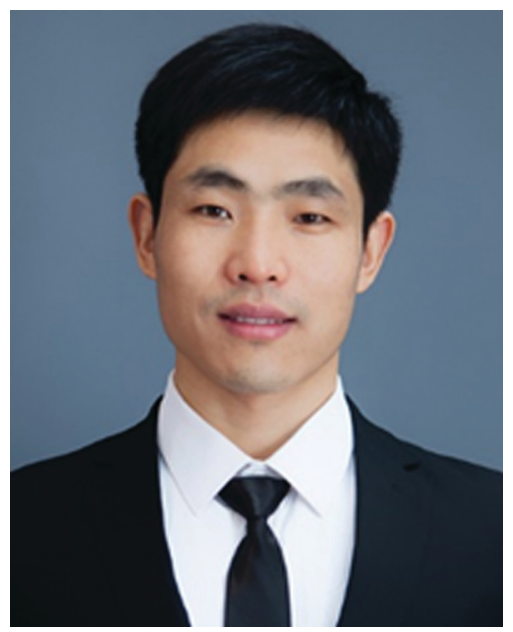

Xuzhou Yan was born in China in 1986. He obtained his PhD degree in Professor Feihe Huang's group at Zhejiang University in 09/2014. Then he joined Professor Peter J. Stang's group as a postdoctoral fellow at the University of Utah from $10 / 2014$ to $07 / 2016$. In $08 / 2016$, he moved to Stanford University to continue his postdoctoral research until 08/2018 under the supervision of Professor Zhenan Bao. In 09/2018, he started his independent career as a full professor at Shanghai Jiao Tong University with research interests in mechanically adaptive supramolecular polymeric materials and light-emitting organometallic materials.

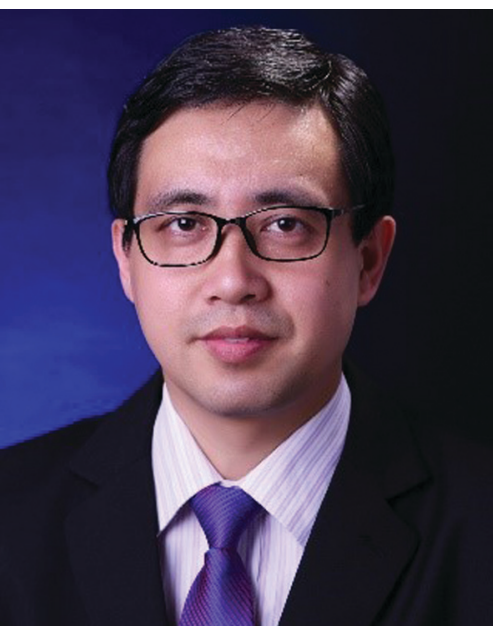

Yi Yan studied chemistry at the College of Chemistry at Jilin University and obtained his Bachelor's degree in 2006 and his PhD degree in 2011 under the guidance of Dr Lixin Wu. After four years' postdoctoral research experience in Canada and the USA, he joined the faculty of the School of Chemistry and Chemical Engineering at Northwestern Polytechnical University in May 2015. His research interests focus on metalcontaining polymers and metallosurfactants, especially their efficient preparation, and exploration of new applications of these materials and their supramolecular self-assembly. Meanwhile, he also likes teaching, especially polymer synthesis experiments and controlled polymerization techniques courses for undergraduates.

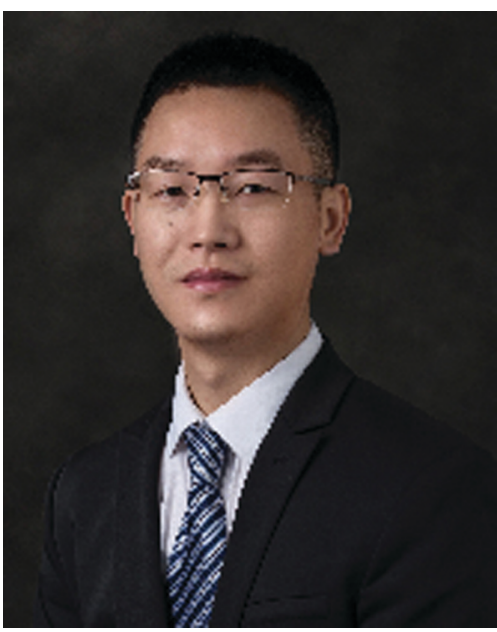

Prof. Dr Da-Gang Yu was born in Jiangxi province, China, in 1986. He received his PhD with Prof. Dr Zhang-Jie Shi from Peking University in 2012. Then he 
carried out postdoctoral research with a Humboldt fellowship in the group of Prof. Dr Frank Glorius, University of Münster. Since 2015, he has been working independently at Sichuan University with support from "The Thousand Young Talents Plan" and the National Natural Science Foundation of China - Outstanding Young Scholars. His research interests mainly focus on novel transformations of
$\mathrm{CO}_{2}$, radical chemistry and novel transition metal catalysis. He received the Thieme Chemistry Journal Award in 2017 and the Chinese Chemical Society Youth Award in 2018. 